\title{
THE INVISIBLE CONSTITUTION (A CONSTITUIÇÃO INVISÍVEL)
}

LAURENCE H. TRIBE

\author{
ALÉCIO SILVEIRA NOGUEIRA ${ }^{1}$
}

RESUMO: Resenha do livro The invisible Constitution, de Laurence H. Tribe, em
que o autor desenvolve a ideia de que por trás do texto "visível" da Constituição
norte-americana existe uma "Constituição invisível", uma "matéria escura" a
orientar a interpretação mais adequada de suas disposições expressas. Isso
explica como as emendas constitucionais coexistem de forma pacífica com
as disposições constitucionais originais e como grande parte das posições
adotadas em face da Constituição norte-americana ao longo da história são
resultado não de seu texto explícito, mas de pistas fornecidas por sua estrutura
invisível. À luz dessa concepção, Tribe analisa diversos julgamentos
paradigmáticos da Suprema Corte e propõe o consórcio de alguns modelos de
construção da parte invisível da Constituição inspirados nas ciências exatas:
são os modelos geométrico, geodésico, global, geológico, gravitacional e
giroscópico, responsáveis pelo delineamento implícito do sistema constitucional.
Tais modelos auxiliam o intérprete na identificação dos postulados tácitos da
Constituição invisível, permitindo a sua constante adaptação às exigências
sociais e históricas.
PLAVRAS-CHAVE: Constituição Norte-Americana; Constituição Invisível; PLAVRAS-CHAVE: Constituição Norte-Am
Suprema Corte; Interpretação Constitucional.

ABSTRACT: Review of The invisible Constitution, by Laurence $\mathrm{H}$. Tribe, in which the author develops the idea of the existence, behind the visible text of the American Constitution, of an "invisible Constitution", or "dark matter", which orientates the proper interpretation of its explicit rules. That makes clear the way constitutional amendments pacifically coexist with original dispositions and how most of the positions adopted with regard to the Constitution along its history result not from its text, but from the hints and clues given by its invisible structure. Under this conception, Tribe analyzes a few leading cases of the Supreme Court and suggests the partnership of some constructing models of the invisible part of the Constitution, inspired by the exact sciences, such as: geometric, geodesic, global, geologic, gravitational and gyroscopic models, responsible for the implicit outlining of the constitutional system. These models

Artigo recebido em 11.05.2011. Artigo aceito para publicação em 31.05.2011.

${ }^{1}$ Graduado em Direito pela Universidade Federal do Rio Grande do Sul - RS. Mestrando em Direito (na área de concentração Fundamentos Constitucionais do Direito Público e do Direito Privado) pela Pontifícia Universidade Católica do Rio Grande do Sul, POA - RS. $1^{\circ}$ Promotor de Justiça da Promotoria de Justiça Cível de Bento Gonçalves - RS. an3305@gmail.com 
help the interpreter in finding out the tacit postulates of the invisible Constitution which allow its constant adaptation to social and historical demand.

KEYWORDS: American Constitution; Invisible Constitution; Supreme Court; Constitutional Interpretation.

SUMÁRIO: Introdução; 1. Sumário da obra; 2. Parte I - Além do visível; 3. Parte II Definindo o terreno; 4. Parte III - Explorações para além do texto; 5. Parte IV O conteúdo da liberdade e da igualdade e os limites do poder governamental; 6. Parte V - Visualizando o invisível; 6.1 Construção geométrica; 6.2 Construção geodésica; 6.3 Construção global; 6.4 Construção geológica; 6.5 Construção gravitacional; 6.6 Construção girosocópica; 6.7 Coda: observações conclusivas; Conclusão e apreciação pessoal; Obras Consultadas.

SUMMARY: Introduction; 1 . Work summary; 2. Part I - Beyond the visible; 3. Part II - Defining the terrain; 4. Part III - Explorations beyond the text; 5. Part IV The content of liberty and equality and the boundaries of government power; 6. Part V - Visualizing the invisible; 6.1 Geometric construction. 6.2 Geodesic construction; 6.3 Global construction; 6.4 Geologic construction; 6.5 Gravitational construction; 6.6 Gyroscopic construction; 6.7 Coda: concluding observations; Conclusion and personal analysis; Consulted Literature.

\section{INTRODUÇÃO}

¿A concepção de uma matéria escura como modelo explicativo para certos fenômenos gravitacionais do universo pode auxiliar na compreensão do que uma Constituição escrita possa ter para além de seu texto? Responder essa indagação é o propósito de Laurence $\mathrm{H}$. Tribe neste seu livro The Invisible Constitution (New York: Oxford University Press, 2008, doravante denominado por sua tradução, A Constituição Invisível); e o autor vai além, na relação com as ciências exatas: na última parte da obra, os cinco modos de construção da Constituição invisível buscam sua inspiração na matemática e a física.

Tribe, contudo, não pretende "aplicar" conceitos de outras áreas científicas ao direito constitucional; esses empréstimos funcionam antes como alegorias para o que ele efetivamente busca dizer com "Constituição invisível": que existe, de fato, na forma como os intérpretes - em geral, do povo à Suprema Corte - admitem certos princípios e mesmo regras constitucionais que não estão no texto constitucional e que com ele não guardam nenhum relação direta de inferência, a pressuposição de que há uma Constituição maior ainda, que estabelece inclusive como deve ser feita a leitura do texto constitucional, posto que não perceptível a uma mera aproximação visual.

Esta resenha tem por objeto a exposição, em breves linhas (dentro do possível, dada a vastidão da abordagem), dos argumentos desenvolvidos n'A Constituição Invisível, conforme a ordem estrutural adotada pelo autor em suas partes e capítulos, razão pela qual aquilo que figurar no corpo principal da explanação terá origem, mesmo que em paráfrases, nas idéias de Tribe e no texto original; os eventuais comentários alheios ao livro virão em notas de rodapé e ao final, numa apreciação pessoal (nossa, portanto) da obra. 
Para simplificar, os títulos serão mencionados em sua forma traduzida, a não ser quando seja interessante manter o original em inglês (o que será feito nas citações textuais); por outro lado, quando fizermos menção a "Constituição", a referência será, naturalmente, à Constituição norte-americana.

Laurence H. Tribe nasceu em Shangai, em 1941. É professor de Direito Constitucional na Universidade de Harvard e um dos mais importantes advogados com atuação perante a Suprema Corte norte-americana, cuja produção acadêmica é mundialmente reconhecida; atua igualmente como consultor jurídico, tendo participado, nessa condição, da campanha de Barack Obama à presidência dos Estrados Unidos. Dentre suas obras mais conhecidas, encontram-se Constitutional choices (1985), On reading the constitution (1991), American constitutional law (1978, 79, 88 e 2000), Abortion: the clash of absolutes (1990) e o objeto desta resenha, The invisible constitution (2008), dentre outros títulos importantes.

\section{SUMÁRIO DA OBRA}

\section{PART I: BEYOND THE VISIBLE}

Identifying "The Constitution"

Distinguishing "The Constitution" from "Constitutional Law"

Remembering Ours Is a Written Constitution

The Variable Role of Interpretive Judicial Precedent

The "Dark Matter"

\section{PART II: DEFINING THE TERRAIN}

Invisibility Defined

Not Necessarily an Ideal Constitution

Constitutional Axioms and Constitutional Theorems

The Politics of Constitutional Invisibility

This Book's Mission: Making Invisibility Visible

Supreme Law, not the Supreme Court

The Constitution Architecture, not its "Construction"

PART III: EXPLORATIONS BEYOND THE TEXT

Invisibility Exemplified: the Moving Fingers Writes

Cleo's Claims

Doubling Back: the Holistic Reading Rule

Two Types of Extratextual Norms

Invisibility Illuminated: a Government of Laws

Invisibility Elaborated: Government of the People, by the People, for the People.

Invisibility Further Illustrated: Suspending Habeas Corpus 
Federalism - and "the Right of the People to Keep and Bear Arms".

States as Sovereigns?

PART IV: THE CONTENT OF LIBERTY AND EQUALITY AND THE BOUNDARIES OF GOVERNMENT POWER

The Substantive "Due Process" Conundrum

The Jagged Road to Equality

The Reapportionment Revolution

Lochner and Selective "Incorporation"

From Liberty of Contract to Forms of Self-Government

Intimate Association and Private Self-Government

Maintaining Boundaries: From Territoriality to Privacy

PART V: VISUALIZING THE INVISIBLE

Once Again: The Ninth Amendments's Rule of Construction

The Inescapable Role of Constitutional "Dark Matter"

The Analogy to Gödel's Incompleteness Theorem

Organizing the Constitution's "Dark Matter"

Geometric Construction

Time's Geometry

A Libertarian Presumption?

Lochner's Legacy Revisited

Geodesic Construction

Global Construction

Geological Construction

Gravitational Construction

Gyroscopic Construction

Coda: Concluding Observations

\section{PARTE I - ALÉM DO VISÍVEL}

Laurence Tribe inicia seu livro com o capítulo Identificando a Constituição, onde observa que os Estados Unidos possuem uma Constituição escrita e incrivelmente breve e que ela contém, segundo alguns, vinte e sete Emendas e, segundo outros, vinte e seis (pp. 2 e 3). A explicação para a divergência está em que a $27^{\mathrm{a}} \mathrm{Emenda}^{2}$, proposta ainda em 1789 , somente

${ }^{2}$ A $27^{a}$ Emenda (No law, varying the compensation for the services of the Senators and Representatives, shall take effect, until an election of Representatives shall have intervened.) não tem, evidentemente, a mesma dimensão das demais, sendo puramente procedimental; daí parte da dificuldade em reconhecê-la como tendo a mesma expressão e importância de suas congêneres. 
foi ratificada em 1992, pelo Estado de Michigan (que completou, assim, o número exigido de 38 Estados para ratificação das emendas constitucionais, segundo a fórmula do art. $V$ da Constituição). Claro que muitos não incluem a $27^{\mathrm{a}}$ Emenda, diz Tribe, por preguiça ou por desatualização; mas outros 0 fazem por uma questão de princípio: eles entendem que, dado o tempo entre a proposta e a sua ratificação, a emenda em questão não faz mais nenhum sentido: teria perdido seu valor. Mesmo Antonin Scalia, Juiz associado da Suprema Corte e textualista declarado, nega validade a essa ratificação, ainda que efetuada de acordo com o texto escrito da Constituição (pp. 3 e 4).

Na verdade, esse é o ponto de partida para a investigação da existência de uma Constituição invisível, porque em nenhum lugar do texto constitucional se diz o que deve estar dentro ou o que deve ficar de fora da Constituição. Aliás, o debate sobre a $27^{\mathrm{a}}$ Emenda pode estender-se a outras três Emendas, da $13^{\mathrm{a}}$ à $15^{\mathrm{a}}$, ratificadas a fórceps (portanto, sem a efetiva anuência dos Estados, que dependiam disso para retornar à União). Nem mesmo a ratificação da própria Constituição foi realizada de acordo com os Artigos da Confederação ${ }^{3}$, pois não houve unanimidade.

O fato, então, é que se a Constituição possui esse nome, é por que algo além de seu texto o diz; algo que explique porque ela foi recepcionada e porque continua sendo fonte primordial de inspiração moral, política e jurídica ainda hoje. É a Constituição invisível que se encarrega dessa tarefa; é ela que revela qual texto visível deve ser aceito como constitucional. Aliás, a $9^{a}$ Emenda, ao dizer que The enumeration in the Constitution, of certain rights, shall not be construed to deny or disparage others retained by the people, reforça inteiramente, mesmo que alguns discordem, essa conclusão.

Tribe, portanto, estabelece a diferença entre a Constituição e o Direito Constitucional (Distinguindo a Constituição do Direito Constitucional), dizendo (p. 9):

"So the visible constitution necessarily floats in a vast and deep and, crucially, invisible - ocean of ideas, propositions, recovered memories, and imagined experiences that the Constitution as a whole puts us in a position to glimpse. And what we glimpse - what we come to comprehend and remake in our own time's image - nurtures the living body of governing law, something more vibrant than an inert blueprint for a possible system of government or a set of political exhortations about a conceivable structure for governance constrained by a potential set of rights and privileges."

\footnotetext{
${ }^{3}$ Os Articles of Confederation and Perpetual Union foram Iniciativa de Benjamin Franklin cerca de um ano antes da independência; depois da independência, a ideia voltou à tona com um comitê liderado por John Dickinson, que então elaborou os Articles of Confederation, aprovados pelo Congresso em 1777 (o estado de Maryland, em 1781, transformou-os em sua própria Constituição) (vide MUZZEY, David Saville. History of the american people. Boston: The Athenaeum Press, 1933. p. 155).
} 
Este conjunto de materiais integra, portanto, o que se denomina Constituição não-escrita (unwritten Constitution). Essa substância invisível da Constituição não é buscada, contudo, na interpretação dos juízes ou da Suprema Corte ou em dados momentos históricos em que ela passaria, segundo alguns, a existir; a preocupação do autor é com qualquer um que interprete a Constituição e com a sua parcela invisível constante, que não dependa de influxos históricos críticos.

No capítulo seguinte, ainda dessa primeira parte (Lembrando que a Nossa Constituição é Escrita), Tribe explicita o assunto de seu livro: "So this is a book about what is "in" the United States Constitution but cannot be seen when one reads only its text" (p. 13). Claro, adverte-nos o autor que não podemos esquecer que há um texto escrito e que ele diferencia a Constituição americana da inglesa, por exemplo, que são camadas e camadas de textos antigos e modernos (que se estende da Magna Carta até a Convenção da União Européia sobre Direitos Humanos) e que se põe, dessa forma, à mercê do Parlamento, que a pode "alterar" mediante uma simples lei. $\mathrm{Na}$ verdade, a Constituição americana, assinada na Filadélfia, em 1787, é um objeto de veneração, mais do que um estatuto legal (p. 14).

Mas, paradoxalmente, em O Papel Variável do Precedente Judicial Intepretativo, Tribe salienta que a interpretação judicial da Constituição é mais flexível do que as interpretações lei federais (p. 15); isso se explica pela maior facilidade de alteração das leis do que da Constituição ${ }^{4}$ - o que cria, em reação, uma tendência a manter as interpretações judiciais anteriores à modificação: as decisões mais antigas são mais firmes no caso de leis no que da Constituição.

Certo, existem os ícones, que podem ser tanto leis quanto precedentes judiciais. Por exemplo, o título VII do Civil Rights Act, de 1964, que trata do assédio sexual no trabalho (on-the-job sexual harassment), tornou-se um marco na história do país, por força da militância de Catherine A. MacKinnon (p. 16); como existem os superprecedentes, dos quais o cases da Suprema Corte Brown v. Board of Education ${ }^{5}$ e Roe v. Wade ${ }^{6}$ são exemplos marcantes. Todavia, as exceções estão aí para provar justamente a regra: a de que existe uma maior plasticidade na interpretação constitucional.

\footnotetext{
${ }^{4}$ Essa dificuldade de emendas à Constituição seria, aliás, uma das explicações para a ausência de direitos sociais na Constituição norte-americana (vide MICHELMAN, Frank. Socioeconomic rights in constitutional law: explaining America way. Disponível em:

<http://www.law.harvard.edu/faculty/workshops/open/papers0708/michelman.paper.pdf.> Acesso em 11.06.2009).

${ }^{5}$ Nesse case, a Suprema Corte reviu o precedente do caso Plessy v. Ferguson, manifestando-se, agora (falamos de 1954), pela inconstitucionalidade da discriminação racial.

${ }^{6}$ Roe $v$. Wade é o controvertido case de 1973 em que se permitiu o aborto sob o argumento da privacy of autonomy, pelo qual a mulher teria o direito e escolher entre manter ou não a gravidez (dentro de um prazo razoável) Cf. GREENBAUM, Jeffrey (org.). Giustizia costituzionale e diritti dell'uomo negli Stati Uniti: i giudici Warren e Burger. Mllano: Giuffrè Editore, 1992. pp. 145/157.
} 
Por fim, ainda nessa primeira parte, o autor introduz a sua concepção de "matéria escura" (dark matter) como compondo a Constituição invisível. A ideia é colhida da física, em que astrônomos que a matéria e a energia "escuras" constituiriam a maior parte do universo que ocupamos ${ }^{7}$; da mesma forma, a Constituição invisível estaria no centro da própria Constituição escrita, definindo seu próprio valor (p. 22).

\section{PARTE II - DEFININDO O TERRENO}

Nesse ponto, sob o título Invisibilidade Definida, Tribe propõe tornar visível a parcial invisibilidade da Constituição no que diz respeito a importantes comandos, princípios e modos de operação além das palavras do texto (p. 25).

Há, segundo o autor, coisas "invisíveis" na Constituição que qualquer um vê; quando o comando constitucional fala que o Congresso não poderá elaborar nenhuma lei que venha a abolir a liberdade de "discurso", todos sabem que ali se encontra não apenas o discurso oral, mas qualquer meio de expressão - música, dança, gestos, novelas, panfletos etc. São invisibilidades triviais. Quando se fala em "imprensa", do mesmo modo há uma invisibilidade trivial, pela qual sabemos que se aplica não apenas à imprensa da época dos constituintes, e outra nem tão trivial assim, pela qual se discute se "imprensa" se refere a um conjunto de instituições e organizações ou, como acredita o autor, a um grupo de funções jornalísticas e editoriais, independentemente de quem as dirige.

Os limites externos dessa invisibilidade trivial, porém, são imprecisos (p. 26). Há grande controvérsia, por exemplo, se o direito à expressão inclui o privilégio de manter o sigilo das fontes jornalísticas ou se a vedação da quarta emenda para busca e apreensões abusivas alcança grampos telefônicos e escutas eletrônicas (a Suprema Corte considerou-as, em 1967, dentro do alcance da quarta emenda). Mas, ainda que haja desacordo quanto a como se deve ler determinada disposição da Constituição, ele recai mais sobre a parte visível da Constituição do que sobre sua parte invisível.

Outra questão é a extração de um princípio contra a discriminação por ponto de vista da primeira emenda (ant-view-point-discrimination, aplicável a situações como aquelas em que militantes que queimam a bandeira dos EUA); eis aqui uma disputa sobre princípios invisíveis que nenhum leitor razoável inferiria da mera leitura do texto. A preocupação específica do livro são justamente esses princípios constitucionais que vão além do que razoavelmente se pode extrair de um documento legal escrito. Há, de fato, coisas que todo mundo sabe, mas que não estão no texto da constituição;

\footnotetext{
${ }^{7}$ Segundo a teoria quântica, por exemplo, haveria no vácuo uma "substância" (substância quântica), associada a uma grande quantidade de energia, denominada zero point energy; ela envolveria e interligaria tudo no universo (cf. ANDREETA, José Pedro; ANDREETA, Maria de Lourdes. Quem se atreve a ter certeza? A realidade quântica e a filosofia. São Paulo: Mercuryo, 2004. p. 179.) ${ }^{8}$ Freedom of speech. A tradução adequada seria "liberdade de expressão", mas, no contexto, falar de sentidos "invisíveis" de "expressão" não faria muito sentido, já que este termo é bem mais amplo do que speech, isto é, discurso.
} 
por exemplo, poucos duvidariam que o princípio da "anti-secessão" integra o próprio coração da Constituição. Está escrita "não com tinta, mas com sangue" (p. 29). Por outro lado, segue Tribe, não é razoável, como muito já se escreveu nesse sentido, recorrer a um corpo de leis "naturais" para a busca desses princípios, as quais, como já dizia Christopher Tiedeman, em 1890 (The Unwritten Constitution of the United States), dependem do momento histórico. Hoje, ninguém mais procura justificar a análise dos princípios recorrendo ao direito natural; Tribe considera muitos dos postulados e teoremas da sua Constituição invisível historicamente contingentes e institucionalmente específicos para que sejam associados aos cânones do direito natural (p. 30).

Seja como for, Tribe não quer a Constituição invisível como algo platônico ou uma "coisa em si mesma" kantiana; ao contrário, ele fala de um construir a Constituição com base no pensarmos o seu conteúdo (p. 34). O que não significa dizer que esse conteúdo seja radicalmente indeterminado, de forma que não nos é permitido encontrar ali qualquer coisa que queiramos.

É o que se retoma nos capítulos Não Necessariamente uma Constituição Ideal e Axiomas Constitucionais e Teoremas Constitucionais: como as interpretações de uma Constituição visível estão sujeitas a limites nãoarbitrários, assim se dá com sua parte invisível, conforme Tribe: "So is the illumination of the invisible Constitution subject to nonarbitrary, although contestable, constraints" (p. 36). Raciocinar sobre a Constituição invisível, portanto, deve pressupor uma certa dose de subjetivismo; mas esse processo deve ser disciplinado, no que é útil a distinção entre teoremas e axiomas, em lógica (p. 37). Axiomas são proposições fundantes presumidas; os teoremas derivam dessas proposições: a Constituição escrita possuiria, desse modo, axiomas explícitos dos quais decorrem os teoremas que constituem parte importante da doutrina.

Mas muito dos princípios considerados constitucionais não se extraem apenas desses axiomas explícitos; parte da Constituição invisível também é axiomática; na verdade, por decorrer de estruturas mais básicas do sistema constitucional, esse axiomas seriam, também eles, teoremas (p. 38).

É importante ainda ver que a Constituição invisível possui relação com a visível; muito da argumentação utilizada em relação à Constituição invisível envolve o debate sobre a parte visível. Na verdade, são os princípios da Constituição invisível que determinam o sentido geral da Constituição escrita (p. 38)

Em A Política da Invisibilidade Constitucional, Tribe esclarece desde logo que a Constituição defendida no seu livro não é de esquerda nem de direita (p. 40); ressalta que ambas as facções costumam denunciar a invocação de uma Constituição invisível como estratégia do adversário de fazer valer seus valores e plataformas políticas - no que estariam equivocadas. Por isso, mais uma vez, o autor nos lembra - agora em A Missão deste Livro: Fazendo o Invisível Visível -que os objetivos da obra são (i) provar, por exemplos 
concretos e teóricos, a realidade e o alcance da Constituição invisível; (ii) depois, exibir os diversos modos de raciocinar para chegar a essa Constituição - não constituindo, seu propósito, contudo, a defesa de uma única versão correta do conteúdo dessa Constituição invisível (p. 42). Para "entender" a Constituição invisível, nesse contexto, é preciso desenvolver uma certa familiaridade com suas linhas gerais e com suas ideias estruturais; com os tipos de valores aos quais ela está vinculada - não necessariamente liberais ou conservadores -, num comprometimento com a dignidade da pessoa humana e o desenvolvimento das aspirações humanas (p. 43).

O papel da Suprema Corte na interpretação constitucional, em especial na imposição do seu entendimento do que a Constituição diz às demais esferas federais e às cortes estaduais (o que pode ser até preferível em determinados assuntos), é retomado para debate em Lei Suprema, não a Suprema Corte. O livro passa ao largo, Tribe insiste em explicitar, das limitações ao poder de revisão judicial ${ }^{9}$; seu objeto é a arquitetura da Constituição invisível, independentemente de quem a interprete (p. 46). Ele não hesita em atacar qualquer decisão judicial que viole o sentido da Constituição não-escrita.

Partindo do texto de Bruce Ackerman, We the People, em que aquele autor estabelece três momentos históricos que forjaram a Constituição tal como o conhecemos hoje (e nenhum deles teria contado com a legitimidade popular: o primeiro, na sua ratificação da própria Constituição; o segundo, na Guerra Civil; o terceiro, no New Deal), e de um outro, de Akhil Reed Amar (America's Constitution: a Biography), para quem cada nova emenda reorienta a leitura integral da Constituição, Tribe, no capítulo A Arquitetura da Constituição, não sua "Construção", pretende identificar a estrutura mais ampla disso que seria a Constituição, sem ater-se a essas explicações insuladas.

Há diferença entre a construção da Constituição e sua arquitetura; Tribe analisa, para prová-la, as constribuições da Suprema Corte sob a orientação de dois de seus Chief Justice: Earl Warren e William Hubbs Rehnquist. Primeiro, os cases Miranda v. Arizona ${ }^{10}$ e Katz v. United States ${ }^{11}$, que demonstram a proteção da Constituição, na visão de Warren, contra os abusos de poder; em segundo lugar, tanto o City of Boerne v. Flores ${ }^{12}$ quanto o Seminole Tribe of Florida v. Florida ${ }^{13}$, do mesmo órgão judicial, que procuraram restringir, embora sem uma determinação escrita da Constituição,

\footnotetext{
${ }^{9}$ Nessa altura, Tribe faz a distinção entre revisão judicial (judicial revision) e supremacia judicial (judicial supremacy): aquela diz com a avaliação da constitucionalidade das leis e de atos administrativos; esta, com os conflitos entre poderes. O autor acaba concordando que uma forma relativamente robusta da judicial review é preferível.

${ }^{10}$ Que, em 1966, obrigou policiais a informarem aos suspeitos detidos os seus direitos constitucionais.

${ }^{11}$ De 1967 , este case reconheceu que a $14^{\mathrm{a}}$ emenda protege a privacy da pessoa, não do local em que se encontra.

12 Impediu a anulação de leis estaduais, por ofensa à legislação federal, como inconstitucionais (pela 14 ${ }^{\mathrm{a}}$ Emenda), a não ser que haja proporcionalidade entre a lei federal atingida e o alcance da inconstitucionalidade nos Estados.

${ }^{13}$ Sobre a impossiblidade de o Congresso revogar imunidades estaduais.
} 
os limites do poder federal. No fundo, não se "constrói" uma Constituição, mas mantém-se uma estrutura invisível que está na sua base (p. 56), ainda que o autor apresente, adiante, o que entende por modos de construção da Constituição invisível.

Os seis modelos que serão expostos depois não explicarão como Warren e Rehnquist chegaram a suas conclusões, mas a arquitetura das regras que ambas as cortes formularam para descrever seu raciocínio e implicações. O resultado disso foi uma Constituição mais protetiva de regras estaduais e dos direitos fundamentais extraíveis das garantias textuais - e a partir da mesma estrutura reconhecida à Constituição invisível (p. 56).

\section{PARTE III - EXPLORAÇÕES PARA ALÉM DO TEXTO}

Em Invisibilidade Exemplificada: os Dedos Móveis Escrevem ${ }^{14}$, o autor identifica que uma das dimensões invisíveis da Constituição é a sua orientação temporal unidimensional: ela é emendada somente daqui para diante, sem se apagarem as palavras antes postas (pp. 59 e 60). Por outro lado, isso tem a implicação de que aquilo que está expresso no texto nem sempre é vinculante (a referência implícita aos escravos no art. $1^{\circ}$, por exemplo); mesmo as Emendas, quando repelem parte da Constituição, jamais retiram dela o texto respectivo (a 21 $1^{a}$ Emenda em relação à secção I da 18a Emenda). Isso ocorre também com a Constituição invisível, e Tribe ilustra a assertiva a partir da dormant commerce clause (que impede abusos das disposições estaduais relativamente a comércio exterior ou interestadual), uma cláusula tida por alguns juízes como fictícia mas que ainda se impõe como "a feature of the constitutional landscape by the early years of the twentieth century and remains so today" (p. 62). De rigor, a tendência de deixar a Constituição visível ou invisível - intacta serve como antídoto para uma amnésia geral contra equívocos da história nacional.

Não é por outra razão que o texto constitucional deve ser lido a partir da visão de seu desdobramento histórico (Demandas de Cleo). Originalistas e textualistas recorrem à história para sustentar o sentido de certas partes ambíguas do texto (ou mesmo para rejeitar certos sentido aparentemente nem tão ambíguos); ninguém pode esperar entender e aplicar qualquer lei sem entender a história por trás dela e da história de sua interpretação (p. 66).

Mas a história constitucional não é hermética; as reações a eventos também contribuem para reorientar os leitores da Constituição, revelando novos problemas e oportunidades (p. 71). A Guerra Civil, a partir do que a escravidão não seria mais apenas "contida", mas abolida, é um bom exemplo. A Grande Depressão da mesma forma; e também the Montgomery Boycott, de 1955, e the March on Washington, liderada por Martin Luther King em 1963.

\footnotetext{
${ }^{14}$ Referência a Rubaiyat, de Omar Khayyam: "Os dedos móveis escrevem e, tendo escrito, continuam movendo-se; nem mesmo toda sua piedade ou engenho os persuadirão de voltar atrás e cancelar meia linha que seja; nem todas as suas lágrimas apagarão uma palavra sequer." (tradução livre nossa dos versos a partir do texto em inglês Tribe apresenta na p. 60).
} 
Por conseguinte, sempre há, na leitura da Constituição, idas e vindas; ela parece mais um o céu à noite, em que o observador deve juntar os pontos luminosos para obter algum sentido, do que uma escavação arqueológica. O céu estrelado revela não apenas a realidade presente, com suas galáxias e estrelas já extintas, mas indica a reunião daquelas condições num dado momento. Assim a Constituição contém elementos esboçados em eras diferentes da história; possui aspectos que podem já ter sido apagados ou transformados (pp. 72 e 73). Os leitores projetam padrões nessa provisão e fazem regras em nome das estruturas invisíveis - o que liberais e conservadores igualmente chamam de postulados tácitos do plano constitucional.

A fórmula dos três quintos ${ }^{15}$ ilustra uma proposição invisível sobre direito constitucional; revela a circunstância na qual a Constituição não significa mais o que seu texto parece dizer. Tratando o texto de uma forma holística, ver-se-á que várias "questões constitucionais" não podem ser resolvidas pelo texto da Constituição, mas por um corpo jurídico que possui um inegável caráter constitucional. É do que o capítulo Voltando Atrás, a Regra da Leitura Holística trata (pp. 74-77).

O autor dá o exemplo da $14^{\mathrm{a}}$ Emenda, que penaliza qualquer Estado que negar o direito de voto aos homens de dado Estado com mais de vinte $e$ um anos. Com as $19^{\mathrm{a}}$ e $26^{\mathrm{a}}$ Emendas, que estenderam, respectivamente, o voto às mulheres e aos maiores de dezoito anos, revela-se a capacidade de futuras emendas alterarem o sentido das provisões anteriores; isso está intimamente relacionado com uma estrutura constitucional ausente do texto em si - o que Tribe chama, lembremos, de Constituição invisível. Cada metaprincípio constitucional - que indica, enfim, como a Constituição deve ser lida precisa ser descoberto fora do texto (ainda que admitíssemos a existência de regras interpretativa dentro do texto, elas reclamariam outras para além dele, numa regressão ad infinitum), como o autor explicita em Dois Tipos de Normas Extratextuais. Uma Constituição que contenha a lista completa de regras para sua própria interpretação é uma impossibilidade lógica (p. 80).

Mas há as normas substantivas criadas pela Constituição invisível, seja no que diga respeito à estrutura de governo, seja com relação aos direitos individuais - o que constitui a ideia mais controvertida do livro, salienta o próprio Tribe. Isto é, mais controvertida para os especialistas em direito constitucional do que exatamente para o resto da população (p. 79).

As normas metaconstitucionais da Constituição invisível seriam, retoma Tribe, a orientação unidirencional e a leitura holística (p. 81); em Invisibilidade Iluminada: um Governo de Leis, o autor passa a buscar provisões constitucionais não-escritas mais substanciais. O exemplo trabalhado é o de uma suposta lei municipal que exija de cada um que pretende adquirir ou

\footnotetext{
${ }^{15}$ Presente no art. $1^{\circ}$, estabelecendo uma diferença, para fins eleitorais, entre pessoas "livres" e os "outros" (no caso, escravos).
} 
alugar um imóvel - ou mesmo nele pernoitar - a aprovação, por escrito, de moradores de um entorno de cerca de 150 metros do imóvel. Ora, não há, aqui, nenhuma ofensa ao devido processo legal (presumindo-se a aprovação regular da lei) ou a qualquer direito fundamental; mas ainda assim poucos não considerariam essa lei inconstitucional, sob o princípio de que temos um "governo de leis, não de homens". Esse princípio ${ }^{16}$ foi reconhecido pela Suprema Corte em Cooper v. Aaron, em 1958, pelo Justice Felix Frankfurter, e trata-se induvidosamente de um princípio que faz parte, ainda assim, da Constituição - da Constituição invisível, frise-se.

No capítulo Invisibilidade Elaborada: Governo do Povo, pelo Povo, para o Povo, encontramos outro princípio constitucional invisível a ser invocado pelo mesmo exemplo. De fato, se a admissão de moradores de um local ficasse ao arbítrio exclusivo da vizinhança, não existira nisso nenhum processo democrático, nenhuma delegação de poder ou de representatividade nessa decisão. Governo do povo, pelo povo, para o povo, foi o que Abraham Lincoln disse no discurso de Gettysburg, em 1863; contudo, quase meio século antes, em 1819, a Suprema Corte, por seu o Chief Justice John Marshall, revisava a validade de um imposto instituído por Maryland (McCulloch v. Maryland) justamente sob o argumento de que apenas o Congresso, em que a nação inteira estava representada, poderia instituir tributos gerais (p. 87). A lei de Maryland era inconstitucional não por uma ofensa ao texto da Constituição em si, mas a um princípio não escrito; princípio que sempre se faz presente mesmo quando as estruturas do federalismo não estão diretamente em causa - mas em qualquer situação em que leis deleguem poderes a indivíduos ou grupos de indivíduos. Esse princípio - o da responsabilidade democrática (principle of democratic accountability, vide p. 90) - não se extrai do texto; ele provém de aspectos invisíveis da Constituição; e constitui um ponto central na história da nação americana.

Tribe vai adiante em Invisibilidade Ilustrada Ainda: Suspendendo Habeas Corpus. Imaginemos, diz ele, que depois dos ataques terroristas de 20010 executivo determinasse o interrogatório de quem quer que fosse, sob o argumento de tratar-se de um suposto inimigo do país, e suspendesse o habeas corpus ou o mandado de segurança em relação a essas pessoas (pp. 92 e 93). Isso, em essência, foi aprovado pelo Congresso por intermédio do Military Comissions Act de 2006. No exemplo dado, porém, suponhamos que o Congresso não tenha autorizado tais disposições. No art. $9^{\circ}$, section 2 , a Constituição permite a suspensão do habeas corpus em caso de invasão e rebelião, quando a segurança geral o exigir; mas não diz quem determinará tais medidas. O entendimento da Suprema Corte no tempo de Guerra Civil era o de que somente o Congresso poderia autorizá-lo. Mas essa orientação não está em lugar algum da Constituição; só pode estar, então, diz Tribe, na

${ }^{16}$ Que não aparece na Constituição dos Estados Unidos, mas no texto da Constituição de Massachussets, de 1780, esboçada por John Adams, e depois repetido por John Marshall no caso Marbury v. Madison, em 1803. 
Constituição invisível (p. 95). Aliás, mesmo com a autorização do Congresso, o reconhecimento de tais poderes ilimitados tornaria a Constituição um conjunto oco de promessas.

Ademais, ¿o que dizer da tortura? Ela é categoricamente proibida pela Constituição, independentemente do argumento de que seja inútil; mas não é caso de aplicação da $8^{\mathrm{a}}$ Emenda (que impede punições cruéis), porque não se trata de punição; nem da quinta emenda (que bane a autoincriminação), porque o objetivo é a extração de informações apenas, não de incriminação da pessoa. O único fundamento para a repulsa à tortura para fins de obtenção de informações é, de mesma forma, a Constituição invisíve ${ }^{17}$.

Já em Federalismo - e o "Direito do Povo de Manter e Portar Armas, Tribe não enfrenta diretamente a questão de que se um ato do Congresso determinando, em Municípios em que a violência por armas de fogo superar certos parâmetros, a restrição na aquisição de armamentos pela população seria inconstitucional ou não em face da $2^{\mathrm{a}} \mathrm{Emenda}^{18}$; o que ele salienta é que a resposta a esse debate não estaria, ela também, na Constituição visível, e sim na Constituição invisível (pp. 98-100).

Para encerramento dessa terceira parte (em ¿Estados como Soberanos?), o autor retoma o exemplo; ele diz que, mesmo que se conclua que a lei do tópico anterior, se aplicada a outras cidades que não Washington, não ofende a segunda emenda (seja porque a aquisição de armas por indivíduos deve estar vinculada a uma milícia, seja porque a regulação em foco seja tida por razoável), ainda assim surge o problema de que a lei estaria tratando os Estados como agências ou departamentos federais. Esse foi o argumento de várias decisões da Suprema Corte nos anos noventa, relativamente a medidas que o Congresso queria impor aos Estados para o controle de material radioativo gerado naquelas unidades federativas e, em outro caso, o controle de armas; mas não havia nada no texto constitucional proibindo essa intervenção; o que havia eram postulados tácitos (ou, mais uma vez, a Constituição invisível, na linguagem do livro). O problema está em que o reconhecimento de que existem disposições não-textuais que regulam as relações entre Estado e indivíduos faz com que também se admitam essas disposições em face dos Estados, e o poder de uma legislatura estadual de criar leis cogentes não faz parte dos poderes concedidos pela Constituição, mas constitui uma prerrogativa ou atributo da estadualidade (statehood); esse poder faz parte do que significa ser um Estado para a Constituição. Por isso, a primeira emenda e o restante do Bill of Rights não se tornariam aplicáveis às legislações estaduais por alguma alquimia constitucional que os converte em entidades "federais" travestidas (p. 104).

\footnotetext{
${ }^{17} \mathrm{O}$ tema voltou à baila com bastante força após a morte de Osama Bin Laden, em $1^{\circ}$ de maio de 2011, quando diversas autoridades governamentais defenderam o uso do "afogamento simulado" (waterboarding) para a obtenção de informações valiosas para a segurança nacional.

${ }^{18}$ Cujo teor é: A well regulated Militia, being necessary to the security of a free State, the right of the people to keep and bear Arms, shall not be infringed.
} 


\section{PARTE IV - O CONTEÚDO DA LIBERDADE E DA IGUALDADE E OS LIMITES DO PODER GOVERNAMENTAL}

Agora, a partir do capítulo A Charada do Devido Processo Substantivo, Tribe ocupa-se da $14^{\mathrm{a}}$ Emenda (due process of law, section I), em especial para a vinculação das legislações estaduais. A Suprema Corte, desde a década de 1870, tem identificado a liberdade de expressão com a liberdade em geral e, daí, com o devido processo legal; do que se extrai que, mesmo que as leis estaduais sejam formalmente perfeitas, elas não são vistas como leis "reais" se violarem os princípios contidos nessa Emenda.

Uns dizem que um devido processo substantivo é um oxímoro; mas a resposta é que o devido processo possui, de fato, uma face substantiva (pp. 110 e 111). Contudo, parece meio forçado considerar que uma lei que venha a banir algumas opiniões, proibir cultos, etc. não seja uma lei. É que, na verdade, se faz a leitura casada com as os privilégios e imunidades dos cidadãos americanos. De qualquer modo, o uso da $14^{\mathrm{a}}$ emenda contra os poderes governamentais tem sido largamente difundido, e não parece que vá haver alteração, num futuro previsível, nesse sentido.

Sob o título O Tortuoso Caminho para a Igualdade, o autor volta a salientar que não existe uma disposição expressa da Constituição que preveja uma ampla proteção para além da vida, liberdade e igualdade - o que também se aplica à previsão "proteção igualitária das leis" (p. 116). Nas primeiras decisões interpretativas da Suprema Corte, por exemplo, a igualdade era vista como algo menor do que o que hoje se considera: bastava que a lei, independentemente de seu conteúdo, se dirigisse a todos; Roberts v. City of Boston $\left(1849^{19}\right.$ ) e Plessy v. Ferguson (1896, em que se estabeleceu o ambíguo princípio do separate but equal) são produtos dessa safra. Aqui, como alhures, a intenção de Tribe é a de frisar que quase todo o debate sobre o sentido da garantia da proteção igualitária - mesmo no contexto histórico de raça ou em outros, como nacionalidade, opções sexuais etc. - tem sido não sobre o que a Constituição diz, mas sobre os seus pressupostos invisíveis.

N'A Revolução da Redistribuição, por seu turno, o texto trabalha com a distinção que Dworkin faz da pretensão à igualdade: de um lado, o direito a ser tratado como um igual e, de outro, o direito e tratamento igualitário. O primeiro conceito diz com as linhas adotadas pelo governo que efetivamente respeitem os grupos e as pessoas, proibindo a subordinação de uns em face dos outros e reconhecendo a dignidade e o respeito devidos a todos pelo Estado; o segundo, com as vantagens que estão sendo divididas e com o acesso a oportunidades iguais - em suma, pelo que cada deve receber uma parte do que o estado disponibiliza (p. 119). Mas o fato é que a Constituição não diz que o acesso à cabine de votação ou à sala de audiências sejam

\footnotetext{
${ }^{19}$ Case também relacionado com questão racial: a demanda pretendia que uma afro-americana pudesse transferir-se para uma escola mais próxima de sua residência e que não era exclusiva para negros. Demanda rejeitada.
} 
"bens" ou "valores" a serem protegidos; nem consagra expressamente o princípio one person, one vote, pedra fundamental da democracia e uma versão da proteção igualitária, segundo a própria Suprema Corte (p. 122). Dificilmente o art. I, section 2, que especifica que os membros da Casa dos Representantes (Câmara dos Deputados) deverão ser escolhidos pelo povo dos vários Estados, poderia corresponder ao princípio em tela, e muito menos à forma especializada da reapportionment, pela qual Rhode Island possui, sabe-se lá por que razão, o mesmo número de senadores que a Califórnia. O propósito de Tribe, em todo caso, é o de demonstrar o quão longe da Constituição visível se pode ir para sustentar os princípios que essas decisões defendem.

A $14^{\mathrm{a}}$ Emenda tem sido entendida, num outro viés, como limites substantivos para o Estado; essa inspiração vem do Bill of Rights (pré-condições, em outras palavras, para uma liberdade ordenada), mas o fato é que ocorreu, em relação a essas direitos do Bill of Rights, uma incorporação seletiva, no sentido de que não se obtém exatamente um consenso de quais os direitos, daquele rol, foram ou não acolhidos pela Emenda. Esse é o tema de Lochner e a Incorporação Seletiva (p. 124). A era Lochner vigorou de 1890 a 1937; nesse período, a liberdade de contrato virou a peça central da limitação da atuação do Estado, e várias legislações estabelecendo proteção para os trabalhadores foram afastadas. No caso Lochner, de 1905, tratou-se dos padeiros: o Estado de New York criou uma lei limitando o trabalho a 10 horas por dia ou 60 por semana, sob dois argumentos: a qualidade do pão produzido e a saúde dos padeiros. A Suprema Corte repeliu esses argumentos. O mesmo raciocínio serviu para que, nas décadas seguintes, leis protetivas dos trabalhadores ou dos consumidores fossem consideradas inconstitucionais. O problema dessa interpretação constitucional é que ela continha, desde o início, tensões internas e externas. As internas vinham de que a Suprema Corte nunca tratou todos os casos de contrato de trabalho de forma equivalente; sempre houve diferenciações para as crianças, mulheres e adultos masculinos; as externas, de que a própria sociedade não concordava com as imensas desigualdades que ictu oculi se constatavam entre os capitalistas e os trabalhadores. Não foi à toa que a Grande Depressão desferiu o golpe final à doutrina: o laissez-faire deixou então de ser um desdobramento lógico do "direito natural à propriedade" (p. 126).

A genealogia da infusão de conteúdos substantivos na $14^{\mathrm{a}}$ Emenda, sob o devido processo legal (primeira parte da section I), decorre de uma interpretação restritiva feita aos privilégios e imunidades previstos pela mesma Emenda (segunda parte da mesma secção), como uma alusão apenas a questões atinentes ao federalismo, como dito em Da Liberdade Contratual às Formas de Autogoverno. O erro do caso Lochner, em verdade, não estava no banimento de liberdades individuais como tendo uma dimensão substantiva, mas em estender a idéia de autogoverno e de liberdade onde elas, pela desigualdade das partes, não poderiam estar presentes: nas condições onde 
esses contratos foram efetuados, não existia liberdade alguma, mas dominação econômica disfarçada; onde não haja essa dominação escamoteada, por outro lado, a proteção contra a intervenção governamental ainda é devida, frisa Tribe (p. 131).

Paralelamente, desde 1920, em plena era Lochner, várias decisões privilegiaram a privacidade e a autonomia pessoais, mesmo tendo relações contratuais como plano de fundo; é o que Tribe explora no capítulo Associação Íntima e Autogoverno Privado. Por exemplo, em Griswold v. Connecticut ${ }^{20}$, a Suprema Corte invocou as "penumbras" da Constituição e permitiu o planejamento familiar às pessoas casadas; em Eisenstadt v. Baird, essa garantia foi estendida aos casais sem a unção matrimonial (p. 133). No caso Roe v. Wade, foi o autogoverno da mulher que teve relevância; em seguida, foram as questões de opção sexual que tomaram corpo. Inicialmente, houve o revés de Bowers $v$. Hardwick, de que Tribe participou, em que a sodomia continuou sendo considerada ilícita; mas, com Lawrence v. Texas, de 2003, a Suprema Corte reviu aquela posição, dando legitimidade às escolhas sexuais íntimas sob o selo do direito à autonomia ${ }^{21}$.

Enfim, em Mantendo os Limites: da Territorialidade à Pivacidade, Tribe retorna à dormant commerce clause, segundo a qual, a partir do art. I, section 8, clause 3, se restringem os direitos de os Estados legislarem sem o sinal verde do Congresso, não lhes sendo permitido agir no seu silêncio (ou na sua "soneca"). O seu exemplo é o de uma lei de Massachussets que penalizasse, em qualquer lugar, quem negasse ou desprezasse as uniões homossexuais reconhecidas naquele Estado. Para atacar a lei de Massachussets, o demandante teria de invocar a idéia de territorialidade: um Estado não poderia atingir cidadãos de outros estados; é a mesma noção que ao longo das decisões da privacy e de Lochner impediu a invasão do autogoverno individual. Idêntico raciocínio se aplicaria a essa invasão criada por um Estado e mesmo às intrusões federais nos Estados. Isso conduz a uma espécie de "teoria de campo unificado" (unified field theory) da Constituição invisível, conforme sua evolução. A base disso é, sem dúvida, conclui Tribe, a $9^{a}$ Emenda (p. 141).

\section{PARTE V - VISUALIZANDO O INVISÍVEL}

Em Mais uma Vez: a Nona Emenda como Regra de Construção, nosso autor reafirma que a diretriz da $9^{a}$ Emenda, dirigida a direitos não-especificamente textualizados, ficou adormecida por cerca de 175 anos; foram William O. Douglas, em Griswold v. Connecticut, julgado pela Suprema

\footnotetext{
${ }^{20}$ A Suprema Corte, nesse case, considerou inconstitucional uma lei do Estado de Connecticut que proibia o uso de anticoncepcionais; o entendimento foi o de que a lei feria a marital privacy (restrita, então, a casais "oficiais"), para o que o juiz Douglas criou a sua penumbra theory, extraindo das primeiras oito emendas - as quais gerariam direitos periféricos (peripherical rights) -, mais 0 disposto na nona emenda, a solução para a lide.

${ }^{21}$ Com relação ao case Bowers, o próprio Justice Lewis F. Powell Jr., autor do quinto e decisivo voto, reconheceu logo em seguida que estava errado...
} 
Corte em 1965, e a opinião concorrente, no mesmo caso, de Arthur J. Goldberg que a retomaram; para Goldberg, trata-se de uma norma de construção ou de interpretação, vinculando autoridades federais e a própria Suprema Corte, orientando-os a não extrair conclusões negativas pelo fato de a Constituição não prever um dado direito. É, assim, um obstáculo à máxima inclusio unius est exclusio alterius (p. 145).

De fato, o que faz a $9^{a}$ Emenda é apontar para fontes de direito além da Constituição, além de seu texto escrito; é a prova da existência de uma matéria escura constitucional (p. 146). Há os que vão mais longe e vêem na $9^{\mathrm{a}}$ Emenda a afirmação de certos direitos particulares, como habitação, alimentação, saúde pública, emprego e meio ambiente saudável; mas Tribe não se arrisca a esse ponto. Outros, em sentido diametralmente oposto, como o Justice Robert Bork, vêem a $9^{\mathrm{a}}$ Emenda como meras manchas de tinta na Constituição (inkblots). Ora, o que faz com que uns a vejam como fonte de direitos materiais ou algo vazio está em que não em nenhum lugar na Constituição Federal uma regra dizendo como ela deve ser lida; e esse é o destino de qualquer regra - ou conjunto de regras - destinada a dar ao intéprete um "mapa": o risco de regressão ad infinitum e de circularidade é inevitável (p. 148).

No capítulo O Inescapável Papel da Matéria Escura Constitucional, Tribe nos aconselha a fugir da ilusão de um texto claro, "iluminado" (p. 149); ele reforça que historicidade como elemento indissociável de qualquer interpretação constitucional válida - e qualquer texto destinado a transmitir sentido para gerações futuras tem como imanente esse problema. Para ilustrar essa questão, Tribe recorre à Analogia ao Teorema da Incompletude de Gödel. O filósofo e matemático Kurt Gödel disse que qualquer sistema de lógica com um número finito de axiomas ricos o suficiente para permitir a expressão das regras básicas de aritmética gerará inevitavelmente proposições que serão verdadeiras, mas que não poderão ser provadas pelas regras lógicas do sistema. A importância disso está em que a inabilidade de se provarem certas proposições num dado sistema não deve ser entendida como sua falsidade; a partir do que Tribe concebe uma regra metaconstitucional não-escrita que diria: Construindo essa Constituição, o leitor deve confinar-se ao texto promulgado (p. 153). Ora, se essa proposição é correta, mas não sendo parte do texto, então ela é falsa; de forma que vícios de circularidades serão criados sempre que se pretender construir uma Constituição apenas a partir de seu texto.

O autor então parte para o que ele chama de Organizando a Matéria Escura Constitucional, em que, a partir da premissa - já inegável - de que existe um Constituição "fora" da Constituição escrita, pretende visualizar como ocorre essa integração de regras, princípios e direitos da Constituição invisível, investigação que deve levar em conta mais a história e a cultura do que a lógica; e que deve ser menos uma questão de teoria do que de observação (p. 155). 
Para esse fim, identificam-se seis modos distintos, mas sobrepostos, de construção na formação da Constituição invisível: o geométrico, o geodésico, o global, o geológico, o gravitacional e o giroscópico ${ }^{22}$. Os primeiros três são essencialmente construtivos (no sentido que estabelecem vínculos entre partes do texto); os últimos três, desconstrutivos (implicam saber como a Constituição iria tornar-se inconsistente sem que certas assunções sejam feitas). Todos os métodos representam o processo mental utilizado para identificar elementos da paisagem constitucional, e podem ser assim resumidos:

\subsection{Construção Geométrica}

Esse método não mais é do que a instrução de "juntar os pontos e traçar as linhas" (p. 157). A partir do Due process of Law e da proteção à vida, propriedade e liberdade, estabelece-se um triângulo; a que se soma mais um quarto ponto, originário do art. II, section 3, pelo qual o Presidente deve cuidar para que as leis sejam fielmente executadas. Isso estabelece uma pirâmide que é uma estrela guia da Constituição invisível, no sentido de que o governo é das leis, não de homens. Ou seja, o executivo deve estar sob a lei; sem essa lei, ninguém pode ser privado de sua liberdade, de sua propriedade e (muito menos) de sua vida. O argumento foi utilizado no case Steel Seizure, contra um ato do presidente Truman apropriando-se de metalúrgicas.

Tribe, exemplificando o uso desse método, comenta o sentido de liberdade (pp. 161 e ss.); de como ela não é, segundo John Marshall Harlan (no case da Suprema Corte Poe v. Ullman), uma séria isolada de pontos, mas um continuum racional; assim, como a $1^{\text {a }}$ Emenda protege a liberdade de expressão e de reunião, e a $4^{a}$ Emenda protege o direito de as pessoas estarem seguras em suas casas, etc., da mesma forma se presume protegido o direito de escolher se vai utilizar contraceptivos (Griswold v. Connecticut e Eisenstadt v. Baird, ambos da Suprema Corte) ou o que fazer com seu parceiro na sua casa (Lawrence v. Texas, também da Suprema Corte). Com essa interpretação, preserva-se um núcleo de dignidade pessoal e interpessoal, de igualdade e autonomia (p. 163).

Claro que outra dimensão vinculada a esse ponto é a do tempo (em Geometria Temporal) - não apenas da história dos Framers da Constituição, ou das Emendas, mas também do sentido que as palavras ganham nesse processo cronológico (p. 164). A $14^{\mathrm{a}}$ Emenda, talvez uma das ricas de todas, teve seu significado alterado ao longo dos eventos do país; o princípio não-escrito do one person, one vote também teve sua dimensão redefinida durante a guerra fria (e, ainda hoje, quando se questiona o sentido da democracia norte-americana). Mas o excesso nesse trabalho de unir os pontos é criticado em Uma Presunção Libertária? e Revisitando o Legado de Lochner, pelo o risco de banalização do sentido da liberdade.

\footnotetext{
${ }^{22}$ Entre as pp. 156 e 157, o livro traz seis gráficos - ou desenhos - que representam tais métodos.
} 
A necessidade de responder a essas questões, aliada ao silêncio do texto, demonstra a existência de um enorme corpo de "matéria escura" que compõe a Constituição; o método geométrico representa "not some magic key with which to unlock the secret of that dark matter but merely the simplest way to organize its points, lines and planes into culturally meaningful forms forms akin to the constellations the ancients superimposed on the starry sky" (f. 171).

\subsection{Construção Geodésica}

Aqui, Tribe serve-se da imagem de Buckminster Fuller, de cúpulas ou domos geodésicos: diversas faces triangulares ou de outras formas, unidas por suas bordas, como a formar "bolha protetivas", cada uma das quais envolve um direito ou princípio central cuja realização depende de um tipo de "espaço vital" protegido das forças externas por uma espécie de escudo adequadamente desenhado (p. 172). A construção geodésica bem representa como a liberdade de expressão tem sido tratada por doutrinas que não são evidentes a partir da Constituição, mas que auxiliam na preservação da essência daquela liberdade. Um exemplo é o da posição da Suprema Corte em New York Times v. Sulivan, de 1963, segundo a qual não se reconheceu indenização a agente público por supostas difamações acerca de sua atividade pública sem uma prova convincente de que as afirmações eram falsas e de que foram divulgadas com esse conhecimento. Também assim em Miranda v. Arizona, de 1966, do mesmo tribunal, relativamente à autoincriminação (a advertência explícita, a ser feita pela autoridade policial, sobre manter-se em silêncio).

Já em Bivens v. Unknown, Unnamed Agents, a Suprema Corte entendeu indenizáveis as violações constitucionais causadas por agente públicos; contudo, desde 1980, a mesma Corte tem sido relutante em aplicar esse precedente. Uma das faces do domo geodésico seria proteger os direitos constitucionais pela implementação efetiva desse remédio, no caso de violação (p. 180).

\subsection{Construção Global}

A Construção Global baseia-se na comparação com a experiência de outras nações. O preenchimento do esqueleto dos direitos humanos básicos da Constituição depende de uma aprendizagem com a experiência de outro países; isso está na origem da própria Constituição e na $14^{a}$ emenda, cuja proteção se dava em nome da humanidade, não dos americanos. Não se trata de usar o direito estrangeiro para resolver os problemas nacionais, mas de buscar auxílio em outras experiências.

Muitos, porém, veem nisso um ataque à soberania; os dois novos Justices, admitidos para a Suprema Corte, John Roberts e Samuel Alito, já se posicionaram nesse sentido restritivo em face do método global. Ocorre, porém, que o antiglobalismo judicial é um reflexo do receio da imigração e do declínio do prestígio americano no resto do mundo - e uma tendência 
francamente xenofóbica; mas, como conclui Tribe o capítulo em questão: "In any event, it is hard to imagine that the attempt to isolate American constitutional thought from events elsewhere in the world will last very long or get very far" (p. 188).

\subsection{Construção Geológica}

Trata-se do primeiro método desconstrutivo; por seu intermédio, as cortes e outros intérpretes têm escavado abaixo da superfície de certos direitos para encontrar suas raízes ou pressuposições e premissas subjacentes (p. 189). Por exemplo, Harlan, em Poe v. Ullman (julgado pela Suprema Corte em 1961), viu no direito à privacidade para atividades consensualmente estabelecidas entre adultos como uma pressuposição da $14^{\mathrm{a}}$ Emenda.

Tribe indica o direito à autogovernabilidade ou autonomia pessoal como base, como premissa invisível de muitos direitos - seja no plano individual seja na esfera interestadual. De fato, a $14^{\mathrm{a}}$ Emenda ficaria sem sentido num contexto em que não se protegesse a autonomia da família, no seu lar, de educar seus filhos como deseja (p. 190). O autor comenta Democracy and Distrust, de John Hart Ely, como sendo um dos mais influentes esforços em encontrar um propósito unitário sob a Constituição, a partir da análise de princípios constitucionais não-escritos e que ainda assim regulam a atividade dos Estados e mesmo de setores da esfera federal, os quais, em última análise, conduzem um latente compromisso constitucional com o bom funcionamento das instituições democráticas (pp. 191 e 192). Entretanto, Tribe não deixa de lançar uma crítica à visão de certo modo "procedimentalista" de tais princípios, em detrimento de uma noção mais estrutural do "devido processo legal" (discutido, nesse capítulo, à luz da autonomia que a mulher teria em interromper sua gravidez). Como o Tribe mesmo o diz, "I formulated the doctrines that emerged as concerned with something neither purely substantive nor purely procedural but 'structural', describing the resulting precedents as instances of 'structural due process'"(p. 196). E os esforços nesse sentido, presentes em alguns julgados da Suprema Corte, bem exemplificam o método geológico de construção (pp. 196 e 197).

\subsection{Construção Gravitacional}

O método gravitacional poderia ser chamado, segundo Tribe, de anti-slippery-slope (p. 198), a funcionar como um atídoto ao argumento da ladeira escorregadia, isto é, aquele pelo qual a concessão de um dado direito poderia implicar consequências desastrosas. Muitos podem ser os exemplos do raciocínio questionado (alguns com uso legítimo): se se demonstra a insuficiência da pena de morte, se demonstraria também a insuficiência das prisões; se se admite o "afogamento simulado" (waterboearding), algo pior pode ser adotado; se se impede a queima da bandeiras, pode-se impedir qualquer crítica aos líderes políticos, etc.

Tribe socorre-se de Albert Einstein e de sua noção de gravidade como curva no espaço-tempo; assim, os princípios redefinem o espaço social em 
que se inserem, o que remete a uma obre do autor, de 1989, chamada The Curvature of Constitutional Space: what Lawyers can Learn from Modern Physics (escrita com o auxílio de Barack Obama). No caso DeShaney v. Winnebago County, da Suprema Corte, o reconhecimento de que as autoridades estatais pudessem ser responsáveis (por omissão) em face de um abuso continuado a uma criança (embora tendo provas de que ele ocorria) implicaria o reconhecimento de que a intervenção na família seria legítima. Entretanto, há possibilidade de reconhecerem situações em que essa intervenção é necessária (e obrigatória), outras em que é vedada e ainda outras em que há discrição. Os limites dessas regiões constituem uma parte importante da Constituição invisível; sua análise depende não de uma aproximação unidimensional, do tipo slippery slope avoidance, mas de uma abordagem gravitacional.

Para o emprego do método, convém levar em conta os extremos, assim como o fato de que os buracos negros são áreas em que as leis universais falham; e tomar em consideração os princípios e suas consequências - e aonde eles podem levar a sociedade. Por exemplo, uma lei que proíba armas nas proximidades de escolas simplesmente porque isso diminuiria 0 rendimento escolar poderia trazer implicações econômicas e prejuízos ao comércio interestadual, permitindo, ao fim, que o Congresso legislasse, por força do art. I, section 8. O resultado seria que, a partir dessa construção, haveria um "buraco negro" e um colapso do sistema, levando o Congresso legislar por qualquer coisa, em detrimento da autonomia dos Estados princípio afirmado pela Suprema Corte desde McCulloch v. Maryland, em 1819. A mesma Corte, no case Lopez v. United States, utilizou esse raciocínio, ao invalidar o Gun-Free Scholl Zones Act; lógica igualmente aplicável à proibição do sexo anal - capaz de levar a intrusões totalitárias nas escolhas pessoais. Justice Jackson resumiu o que seria o método gravitacional, ao falar da primeira emenda, ressaltando que "the Constitution was designed to avoid these ends by avoiding these begginings" (p. 205).

O método gravitacional dá suporte a várias decisões recentes sobre a privacy; aliás, esse conjunto de direitos mostra-se decorrente também dos métodos geométrico, geodésico (com um dos direitos servindo de escudo para outros), geológico e global. Isso demonstraria que essas abordagens se apoiam mutuamente; e, quando isso ocorre, torna-se mais evidente ainda que um determinado direito tem suas raízes na Constituição invisível (p. 206).

\subsection{Construção Giroscópica}

Enfim, o modo final, dito "giroscópico", revela que a Constituição, assim como um Hanukah dreidel ${ }^{23}$, é dotada de uma força centrípeta e centrífuga, ambas a criarem um centro de equilíbrio (p. 207). O princípio que impede a expulsão de Estados da união cria uma força centrípeta que torna a união

\footnotetext{
${ }^{23}$ Espécie de dado-pião, dotado de quadro lados com letras hebraicas, utilizados em jogos de azar durante o feriado de Chanukah.
} 
um conjunto estável e não apenas um agregado de unidades federativas; centrífuga é a força, por outro lado, do federalismo, que impede a invasão da autonomia dos Estados.

A dificuldade de emendas à Constituição faz com que a interpretação de disposições constitucionais seja mais permeável a revisões do que as interpretações legais, como já observado por Tribe; essa projeção para o futuro é compensada, de outro lado, pelo stare decisis ${ }^{24}$. O problema é que tratar esse princípio como integrante da Constituição invisível contribui para tornar "espessa" (sticky) a interpretação constitucional, restringindo alterações - o que parece um tanto paradoxal, mas somente se traçarmos uma linha muito clara entre a Constituição e o direito constitucional e se ignorarmos a "sabedoria coletiva do passado". Um cós corolários do livro, porém, são de que essa linha é esfumaçada e de que o passado, mesmo não se mostrando muito visível à distância, tem suas razões legítimas nesse processo interpretativo (p. 209).

\subsection{Coda: Observações Conclusivas}

Tribe conclui a exposição de seus "modos" de formação de uma Constituição invisível dizendo que muito do que todos entendem fazer parte da Constituição não integra, na verdade, seu texto, pelo que é induvidosa a existência de uma matéria escura, de uma parte invisível da Constituição em sentido amplo. Descobrir os postulados tácitos da Constituição é tarefa de todos que a tomam por sua diretriz interpretativa.

O propósito do autor é o de fazer com que se deixe de discutir se há ou não uma Constituição invisível para discutir-se o que ela contém; mesmo que esse consenso seja difícil e se dê em níveis por demais abstratos, ainda assim a tentativa deve ser feita. Aliás, não é de estranhar-se que essa ausência de consenso seja comum também em relação a textos escritos da Constituição: não é a Constituição invisível ou a Constituição visível que criam divergências sobre seu sentido, mas a ambiguidade e multidimensão que são inerentes a ambas.

O autor encerra o livro referido o mito da caverna, de Platão, dizendo que "everything we see is a shadow cast by that which we do not see" (p. 211).

\section{CONCLUSÃO E APRECIAÇÃO PESSOAL}

Não é difícil perceber o valor da concepção de Laurence Tribe, em seu The Invisible Constitution, para qualquer sistema constitucional. A ideia de

\footnotetext{
${ }^{24}$ Pelo princípio do stare decisis (cuja formulação completa é stare decisis et non quieta movere, ou seja, mantenha-se a decisão e não se altere o que está decidido), a decisão judicial no âmbito da common law exerce duas funções: ela põe termo à disputa das partes e gera um precedente para o futuro; além disso, implica o respeito à comunidade, ao passado e à previsibilidade judicial, ao mesmo tempo em que permite a correção de interpretações equivocadas. O stare decisis insere-se, por isso, num contexto de tensão dialética entre estabilidade e mudança, não correspondendo à ideia usual de que constitui um promovedor do conservadorismo e da rigidez jurisdicional. Vide RE, Edward D. Stare decisis. Trad. Ellen Gracie Northfleet. In Revista da Associação dos Juizes do Rio Grande do Sul - AJURIS. Porto Alegre, v. 60, 1994.
} 
que existe algo além do texto escrito não é apenas uma exigência de lógica hermenêutica (na medida em que sempre haverá uma norma não-escrita para orientar a interpretação daquelas positivadas), mas consiste numa boa explicação para como ocorre, de fato, a aplicação do Direito Constitucional.

Para o caso brasileiro, a referência parece dotada de especial significação, na medida em que - mutatis mutandis - a previsão do art. $5^{\mathrm{a}}$, $\S 2^{\circ}$, da Constituição Federal de 1988 é similar à da $9^{a}$ Emenda da Constituição norte-americana, permitindo a investigação, na "matéria escura" que permeia e orienta o texto constitucional, de outros direitos e princípios não expressamente ali previstos. Fatores históricos, culturais e estruturais - e, empregando a linguagem de Tribe, os métodos geométrico, geodésico, global, geológico, gravitacional e giroscópico - são imprescindíveis nessa análise, para que se evite sempre a alegação de arbitrariedade na escolha da relação inevitável (na verdade, amplamente desejável) que se estabelece entre o texto escrito e a Constituição invisível - cuja existência, se é indiscutível do ponto de vista da tradição judicial da Suprema Corte dos Estados Unidos, ainda é vista com reservas pelo jurista brasileiro, como se sua assunção estivesse a serviço de forças ideologicamente orientadas.

É claro que o livro não soluciona muitas questões, nem oferece uma fórmula, no sentido que a empregam as ciências exatas, para a interpretação constitucional - na verdade, nem seria o seu propósito, como expressamente dito por Tribe. Mas isso parece frustrar em certa medida a expectativa criada em torno dos métodos apresentados pelo autor (que busca inspiração justamente nas ciências exatas), trabalhadas de forma um tanto livre e antes alegórica, cuja aplicabilidade na interpretação constitucional parece ainda pecar por uma certa "abertura excessiva", a permitir várias construções argumentativas num ou outro sentido. Na verdade, a própria natureza do objeto estudado, ao nosso ver, não autoriza a construção de modelos de verificação de falseabilidade no sentido científico estrito, pelo que os critérios interpretativos apresentados - seja por Tribe, seja por quem se dedique ao estudo do Direito - sempre serão aproximativos e dependerão, em maior ou menor grau, da coesão argumentativa empregada na sua verificação.

Por outro lado, a busca de limites não-arbitrários para a interpretação jurídica, sobretudo em matéria constitucional, representa não apenas um ideal ou um desejo de qualquer intérprete - mas a garantia da sobrevivência de muitos princípios constitucionais implícitos que, sem estarem amparados por tais métodos, seriam de pronto desconsiderados como devaneios programáticos; nesse sentido, põe-se como dever de qualquer operador do Direito Constitucional (não apenas dos Tribunais Superiores, diga-se de passagem, mas onde exista o controle difuso da Constituição) a demonstração de que as garantias extraídas da fonte invisível de que fala Laurence Tribe não são produto de poesia jurídica, mas do próprio direito em seu sentido mais técnico. 


\section{OBRAS CONSULTADAS}

ANDREETA, José Pedro; ANDREETA, Maria de Lourdes. Quem se atreve a ter certeza? A realidade quântica e a filosofia. São Paulo: Mercuryo, 2004.

GREENBAUM, Jeffrey (Org.). Giustizia costituzionale e diritti dell'uomo negli Stati Uniti: i giudici Warren e Burger. Trad. Cristina Tarpani Origlio. Milano: Giufrè Editore, 1992.

LISBOA, Wladimir Barreto. Thomas Hobbes e a controvérsia acerca da interpretação da lei: uma questão jurídica vista à luz do commomwealth hobbesiano. In: Constituição, sistemas sociais e hermenêutica: programa de pós-graduação em Direito da UNISINOS: mestrado e doutorado. Orgs. Lenio Luiz Streck, José Luis Bolzan de Morais; Ovídio Areaújo Baptista da Silva et. al. Porto Alegre: Livraria do Advogado Editora. Porto Alegre: 2008. pp. 271-279.

MACHADO, Anna Rachel (coord.). Resenha. São Paulo: Parábola Editorial, 2004.

MICHELMAN, Frank. Socioeconomic rights in constitutional law: explaining America way. Disponível em:

<http://www.law.harvard.edu/faculty/workshops/open/papers0708/michelman.paper.pdf.> Acesso em 11.06.2009.

MUZZEY, David Saville. History of the American People. Boston: The Athenaeum Press, 1933.

RE, Edward D. Stare Decisis. Trad. Ellen Gracie Northfleet. In Revista da Associação dos Juizes do Rio Grande do Sul - AJURIS. Porto Alegre, v. 60, 1994.

TRIBE, Laurence. The Invisible Constitution. New York: Oxford University Press, 2008. 